REVIEW ARTICLE

\title{
Molecular Basis of Pulmonary Hypertension
}

\author{
Ambrin Farizah Babu* \\ Molecular Life Sciences, University of Lausanne, Switzerland
}

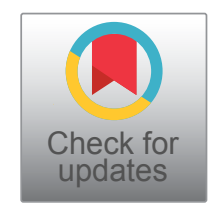

*Corresponding author: Ambrin Farizah Babu, Molecular Life Sciences, University of Lausanne, Switzerland

\begin{abstract}
Pulmonary hypertension is a life threatening incurable disorder. The advances in physiology, genetics, and molecular biology have greatly improved our understanding of the cellular and molecular mechanisms underlying the disorder. In this review, the recent progresses in the understanding of molecular mechanism are presented. Many studies show that pulmonary hypertension is caused due to mitochondrial dysfunction, endothelin-1, prostacyclin and serotonin. These findings and their exploitation will hold promise to find novel treatment options for patients.
\end{abstract}

\section{Keywords}

Molecular mechanism, Pulmonary Hypertension, Mitochondrial dysfunction, Endothelin-1, Prostacyclin, Serotonin

\section{Introduction}

\section{Disease overview}

Pulmonary hypertension (PH) is a type of high blood pressure that affects the arteries in the lungs and the right side of the heart. It reflects the pressure the heart must exert to pump blood from the heart through the arteries of the lungs. This is in contrast with the systemic blood pressure (commonly known as blood pressure, high blood pressure or hypertension) which measures the pressure in the brachial artery while the left side of the heart pumps oxygen-rich blood from the lungs into the rest of the body, measured with a traditional arm cuff [1]. The symptoms of the disease include irregular heartbeat, racing pulse, passing out or dizziness, progressive shortness of breath during exercise or activity, and difficulty breathing at rest [2]. The classification of $\mathrm{PH}$ and their causes are shown in Table 1. $\mathrm{PH}$ is clinically diagnosed when mean pulmonary artery pressure is greater than $25 \mathrm{mmHg}$ at rest or 30 $\mathrm{mmHg}$ during exercise. It is characterized by an increase in pulmonary vascular resistance that ultimately leads to right-heart failure and death. Although it is a rare disease, it is a progressive and often a fatal lung disorder for which there is no cure [3].

This review focusses on some recent studies of the molecular causes of PH. A greater understanding of the cellular and molecular biology of the disease may provide a useful platform to devise novel treatment options for patients.

\section{Mitochondrial dysfunction}

Mitochondria plays an important role in disease pathogenesis. lqbal, et al., 2001 [4] hypothesised that mitochondrial dysfunction contributes to pulmonary hypertension. Mitochondria, despite being a major site of cellular oxygen consumption, is also a major site of cellular oxidative stress. This is due to the generation of reactive oxygen species (ROS), which can thereby contribute to oxidative stress observed with pulmonary hypertension [5-8]. Rather than being completely reduced to water, it has been estimated that 1 to $4 \%$ of oxygen consumed by mitochondria is incompletely reduced to ROS (e.g., $\mathrm{O}_{2}$ - and $\mathrm{H}_{2} \mathrm{O}_{2}$ ) due to leakage of electrons from the respiratory chain $[9,10]$.

Thus, due to the great demand that is placed on mitochondria to support the rapid rates of growth, combined with the propensity of mitochondria to produce ROS, mitochondria may be extremely important in contributing to oxidative stress associated with pulmonary hypertension [4].

The tissues and organs affected by pulmonary hypertension were found to share a common metabolic anomaly linked to mitochondrial dysfunction: The suppression of the mitochondrial glucose oxidation (pro-

Citation: Babu AF (2019) Molecular Basis of Pulmonary Hypertension. Int J Clin Cardiol 6:145. doi. org/10.23937/2378-2951/1410145

Accepted: May 29, 2019; Published: May 31, 2019

Copyright: (c) 2019 Babu AF. This is an open-access article distributed under the terms of the Creative Commons Attribution License, which permits unrestricted use, distribution, and reproduction in any medium, provided the original author and source are credited. 
Table 1: Classification and causes of $\mathrm{PH}$ [36].

\begin{tabular}{|c|c|}
\hline Types & Causes \\
\hline Group 1 Pulmonary Arterial Hypertension & $\begin{array}{l}\text { - } \\
\text { - Inherited: Heritable (HPAH) } \\
\text { - } \quad \text { Caused by drugs/toxins } \\
\text { - } \quad \text { Caused by conditions(APAH): HIV, Liver disease etc., }\end{array}$ \\
\hline Group 2 Pulmonary Hypertension & $\begin{array}{l}\text { - } \mathrm{PH} \text { with left heart disease } \\
\text { - Caused by conditions that affect the left side of the heart: Mitral valve } \\
\text { disease, High blood pressure }\end{array}$ \\
\hline Group 3 Pulmonary Hypertension & - $\mathrm{PH}$ associated with lung diseases: COPD, Interstitial lung disease \\
\hline Group 4 Pulmonary Hypertension & $\begin{array}{l}\text { - Caused by blood clots in the lungs } \\
\text { - Caused by blood clotting disorders }\end{array}$ \\
\hline Group 5 Pulmonary Hypertension & $\begin{array}{l}\text { - Caused by unclear multifactorial mechanisms: } \\
\text { Blood disorders } \\
\text { System disorders } \\
\text { Metabolic disorders } \\
\text { Other conditions like tumor }\end{array}$ \\
\hline
\end{tabular}

cess through which sugar glucose is converted into energy) and a subsequent increase in cytoplasmic glycolysis. In this sense, the authors suggest that the increase in mitochondrial glucose oxidation may improve $\mathrm{PAH}$ pathogenesis. In fact, it has been shown that treatment with dichloroacetate or trimetazidine (both drugs that stimulate glucose oxidation) can improve the right-ventricular function, which is the most important predictive factor for $\mathrm{PAH}$ [11].

\section{Prostacyclin}

Prostacyclin belongs to the endogenous prostanoids family. It is produced from arachidonic acid in a multistep process involving the enzymes prostacyclin synthase and cyclooxygenase (COX) [12-14]. In the pulmonary circulation, prostacyclin is released by endothelial cells in the pulmonary artery [15].

Prostacyclin synthesis is decreased in endothelial cells from PAH patients. Analysis of urinary metabolites of prostacyclin showed a decrease in the amount of excreted 6-ketoprostaglandin $\mathrm{F} 1 \alpha$, a stable metabolite of prostacyclin, in patients with idiopathic PAH [16]. Moreover, pulmonary endothelial cells of PAH patients are characterized by reduced expression of prostacyclin synthase [17], and prostacyclin therapy has been shown to improve hemodynamics, clinical status, and survival of patients displaying severe PAH [18].

\section{Endothelin-1}

Endothelin-1 (ET-1) is a peptide isolated from vascular endothelial cells. It has the most potent vasoconstricting activity and is also a mitogen for smooth-muscle cells in vitro $[19,20]$. It is found to be elevated in heart failure states as well as in pulmonary arterial hypertension (PAH). The pulmonary production of ET-1 may contribute to the vascular abnormalities associated with $\mathrm{PH}$ [21]. Patients with $\mathrm{PH}$ have significantly higher plasma ET-1 concentrations than healthy controls
$[22,23]$. Hence ET-1 receptor blockade could be used for treatment.

\section{Nitric Oxide}

Nitric oxide is a low molecular weight, oleophilic, very fast reacting endogenous free radical. It is a vasodilator and can inhibit platelet aggregation, thrombosis, and remodelling [24]. It is capable of modulating vascular injury and interrupting the elevation of pulmonary vascular resistance selectively. However, it can also produce cytotoxic oxygen radicals and exert cytotoxic and antiplatelet effects. The balance between the protective and adverse effects of nitric oxide is determined by the relative amount of nitric oxide and reactive radicals. $\mathrm{Ni}$ tric oxide has been shown to be clinically effective in the treatment of pulmonary hypertension and other heart diseases. Additionally, new therapeutic modalities for the treatment of pulmonary hypertension, phosphodiesterase inhibitors, natriuretic peptides and aqueous nitric oxide are also effective for treatment of elevated pulmonary vascular resistance [25].

\section{Serotonin}

Serotonin, also known as 5-hydroxytryptamine, is a mitogen secreted from neuroendocrine cells in the gut, and carcinoid tumours are a source of increased production $[26,27]$. Serotonin from the gastrointestinal tract is normally metabolised by the liver before it reaches the lungs, and it is also effectively removed by the lungs. Both these organs usually localise the effects of serotonin to the circulation of origin, except when abnormal channels of communication exist, as in portal hypertension, or when metabolic capacity is overwhelmed. Lack of removal of vasoactive substances by the liver could help to explain the association between pulmonary hypertension, portal hypertension, and liver diseases [28,29].

On a molar basis, serotonin is the most potent 
pulmonary vasoconstrictor identified to date in humans [30], but in the systemic vasculature it causes profound vasodilation [31]. These differing effects on the two circulations are similar to those of hypoxaemia and the effects of serotonin are intensified under hypoxaemic conditions and by the administration of catecholamines.

The vascular adverse effects of serotonergic amines such as ergotamine are exacerbated in liver disease [32]. The ability of the endothelial cells of the lungs to metabolise amines may also be reduced in disease states, probably because of impairment of amine oxidase enzymes [33,34]. Such impairment results in raised circulating amine levels, which may provide early evidence of endothelial dysfunction in pulmonary hypertension before morphological changes are apparent (Table 1).

\section{Conclusion}

A great progress has been made in the identification and the understanding of the molecular basis of $\mathrm{PH}$. However, we are still far away from a comprehensive understanding of this deadly disease. This is true for the proliferative abnormalities of the pulmonary vasculature and is even truer for the pathogenetic sequelae underlying right ventricular hypertrophy and failure [35]. There is a need for a greater understanding of the mechanisms of $\mathrm{PH}$. This would, in the future, yield improved treatments options for patients.

\section{References}

1. http://www.heart.org/HEARTORG/Conditions/ HighBloodPressure/AboutHighBloodPressure/What-isPulmonaryHypertension_UCM_301792_Article.jsp\#

2. https://my.clevelandclinic.org/health/diseases_conditions/ hic_Pulmonary_Hypertension_Causes_Symptoms Diagnosis_Treatment

3. http://grants.nih.gov/grants/funding/modular/modular.htm

4. Iqbal MD, Cawthon RF, Wideman Jr, WGBottje (2001) Lung mitochondrial dysfunction in pulmonary hypertension syndrome. I. Site-specific defects in electron transport chain. Poultry Sci 80: 485-495.

5. Enkvetchakul B, W Bottje, N Anthony, R Moore, W Huff (1993) Compromised antioxidant status associated with ascites in broilers. Poultry Sci 72: 2272-2280.

6. Bottje WG, RF Wideman Jr (1995) Potential role of free radicals in the etiology of pulmonary hypertension syndrome. Poult Avian Biol Rev 6: 211-231.

7. Bottje WG, B Enkvetchakul, R Moore, R McNew (1995) Effect of a-tocopherol on antioxidants, lipid peroxidation, and the incidence of pulmonary hypertension syndrome (ascites) in broilers. Poultry Sci 74: 1356-1369.

8. Diaz-Cruz A, C Nava, R Villanueva, M Serret, R Guinzberg, et al. (1996) Hepatic and cardiac oxidative stress and other metabolic changes in broilers with the ascites syndrome. Poultry Sci 75: 900-903.

9. Chance B, H Sies, A Boveris (1979) Hydroperoxide metabolism in mammalian organs. Physiol Rev 59: 527-605.

10. Boveris A, B Chance (1973) The mitochondrial generation of hydrogen peroxide. Biochem J 134: 707-711.
11. http://pulmonaryhypertensionnews.com/2015/08/20/ highlights-new-theory-pulmonary-arterial-hypertensionmetabolic-theory/

12. Deng H, Wu J, So SP, Ruan KH (2003) Identification of the residues in the helix $F / G$ loop important to catalytic function of membrane-bound prostacyclin synthase. Biochemistry 42: 5609-5617.

13. Ruan KH (2004) Advance in understanding the biosynthesis of prostacyclin and thromboxane A2 in the endoplasmic reticulum membrane via the cyclooxygenase pathway. Mini Rev Med Chem 4: 639-647.

14. Lin Y, Wu KK, Ruan KH (1998) Characterization of the secondary structure and membrane interaction of the putative membrane anchor domains of prostaglandin 12 synthase and cytochrome P450 2C1. Arch Biochem Biophys 352: 78-84.

15. Ruan KH, Wu J, Cervantes V (2008) Characterization of the substrate mimic bound to engineered prostacyclin synthase in solution using high-resolution NMR spectroscopy and mutagenesis: Implication of the molecular mechanism in biosynthesis of prostacyclin. Biochemistry 47: 680-688.

16. Christman BW, McPherson CD, Newman JH (1992) An imbalance between the excretion of thromboxane and prostacyclin metabolites in pulmonary hypertension. $\mathrm{N}$ Engl J Med 327: 70-75.

17. Tuder RM, Cool CD, Geraci MW (1999) Prostacyclin synthase expression is decreased in lungs from patients with severe pulmonary hypertension. Am J Respir Crit Care Med 159: 1925-1932.

18. Marc Humbert, Nicholas W Morrell, Stephen L Archer, Kurt R Stenmark, Margaret R MacLean, et al. (2004) Cellular and molecular pathobiology of pulmonary arterial hypertension. Journal of the American College of Cardiology 43: S13-S24.

19. Yanagisawa $M$, Kurihara $H$, Kimura $S$, Tomobe $Y$, Kobayashi M, et al. (1988) A novel potent vasoconstrictor peptide produced by vascular endothelial cells. Nature 332: 411-415.

20. Komuro I, Kurihara H, Sugiyam T, Takaku F, Yazaki Y (1988) Endothelin stimulates c-fos and c-myc expression and proliferation of vascular smooth muscle cells. FEBS Lett 238: 249-252.

21. Patrice Cacoub, Richard Dorent, Patrick Nataf, Alain Carayon, Marc Riquet, et al. (1997) Endothelin-1 in the lungs of patients with pulmonary hypertension. Cardiovasc Res 33: 196-200.

22. Cacoub P, Dorent R, Maistre G, Nataf P, Carayon A, et al. (1993) Endothelin-1 in primary pulmonary hypertension and the Eisenmenger syndrome. Am J Cardiol 71: 448-450.

23. Stewart DJ, Levy RD, Cernacek P, Langleben D (1991) Increased plasma endothelin-1 in pulmonary hypertension: Marker or mediator of disease. Ann Intern Med 114: 464-469.

24. Cooke JP, Dzau VJ (1997) Nitric oxide synthase: Role in the genesis of vascular disease. Annu Rev Med 48: 489-509.

25. Sim JY (2010) Nitric oxide and pulmonary hypertension. Korean Journal of Anesthesiology 58: 4-14.

26. Perry RR, Vinik Al (1996) Endocrine tumors of the GI tract. Annu Rev Med 47: 59-62.

27. Hart CM, Block ER (1989) Lung serotonin metabolism. Clin Chest Med 10: 59-70.

28. Lockhart A (1985) Pulmonary arterial hypertension in portal hypertension. Clin Gastroenterol 14: 123-138. 
29. Mandell MS, Groves BM (1996) Pulmonary hypertension in chronic liver disease. Clin Chest Med 17: 17-33.

30. Heffner JE, Sahn SA, Repine JE (1987) The role of platelets in the adult respiratory distress syndrome. Culprits or bystanders? Am Rev Respir Dis 135: 482-492.

31. Comroe JH, van Lingen B, Stroud RC (1953) Reflex and direct cardiopulmonary effects of $5 \mathrm{OH}$ tryptamine (serotonin). Their possible role in pulmonary embolism and coronary thrombosis. Am J Physiol 173: 379-386.

32. Katz Al, Massry SG, Tikvah P (1966) Arteriospasm after ergotamine tartrate in infectious hepatitis. Arch Intern Med 118: $62-64$.
33. Block ER, Stalcup A (1982) Metabolic functions of the lung. Of what clinical relevance? Chest 81: 215-223.

34. Boor PJ, Hysmith RM, Sanduja R (1990) A role for a new vascular enzyme in the metabolism of xenobiotic amines. Circ Res 66: 249-252.

35. Seeger W, Pullamsetti SS (2013) Mechanics and mechanisms of pulmonary hypertension-Conference summary and translational perspectives. Pulm Circ 3: 128-136.

36. (2015) Classification of PH. 